\title{
'Delicious': An Early-ripening, Self-fertile, Multipurpose Black-fruited Muscadine Grape
}

\author{
Dennis J. Gray ${ }^{1,4}$, Zhijian T. Li², Sadanand A. Dhekney ${ }^{3}$, \\ and Donald L. Hopkins ${ }^{1}$ \\ Mid-Florida Research and Education Center, University of Florida/IFAS, \\ 2725 Binion Road, Apopka, FL 32703-8504
}

\section{Charles A. Sims ${ }^{1}$}

Food Science and Human Nutrition, University of Florida/IFAS, P.O. Box 110370, Gainesville, FL 32611-0370

Additional index words. disease resistance, fruit breeding, Vitis rotundifolia

Delicious (Vitis rotundifolia Michx.) is a new muscadine grape cultivar being released by the University of Florida that is blackfruited, early and even ripening, high-yielding, and disease-resistant (Fig. 1). It has excellent taste and texture with an edible skin, making it well-suited for fresh fruit consumption. It also has potential for wine production. The berries have a dry stem scar and harvest readily with mechanical shaking.

\section{Origin}

'Delicious' originated from a cross between AA10-40, a self-fertile, bronzefruited selection with medium-sized $(7 \mathrm{~g})$ berries, and CD8-81, a self-fertile, blackfruited selection with larger $(9 \mathrm{~g})$ berries (Fig. 2). AA10-40 originated from a cross between 'Summit', a bronze-fruited female, and AD3-42, a self-fertile progeny of 'Carlos' and 'Welder', which are both bronzefruited and self-fertile. CD8-81 originated from a cross between 'Fry', a bronze-fruited female, and 'Southland', a self-fertile blackfruited cultivar. Based on cultivar descriptions provided by Mortensen (2001), the black berry color likely originated from 'Southland' and the self-fertile trait came from 'Carlos', 'Southland', and/or 'Welder'. The original seedling was planted in 1993 . Because of its high fruit quality, self-fertile

Received for publication 5 May 2008. Accepted for publication 12 June 2008.

This research was supported by the Florida Agricultural Experiment Station, the Florida Grape Grower's Association, and the Florida Department of Agriculture and Consumer Services' Viticulture Trust Fund.

We are indebted to Bob Paulish, past President of the Florida Grape Grower's Association, for suggesting the name 'Delicious' based on the impressions of visitors to his vineyard who sampled the fruit.

${ }^{1}$ Professor.

${ }^{2}$ Senior Biological Scientist.

${ }^{3}$ Assistant in Grape Biotechnology.

${ }^{4}$ To whom reprint requests should be addressed; e-maildjg@ufl.edu. flowers, early yield, and disease resistance, it was propagated for further trial as Fla. AA4-20. It was compared with 10 commercial cultivars (blackfruited Alachua, Nesbitt, Southern Home, Supreme and bronze-fruited Darlene, Dixie Fry, Pam, Summit, Triumph) and nine experimental selections by establishing it in a randomized field trial containing 20 vines of each variety/selection at the Mid-Florida Research and Education Center, Apopka, in 2001 and was evaluated over five fruiting seasons. Vines in the field trial were spaced $3.3 \mathrm{~m}$ apart and trained to a single-wire trellis with two cordons per vine. Fruiting spurs were pruned to four buds in February of each year. Drip irrigation was used and vines were fertilized by broadcast application of $6 \mathrm{~N}-6 \mathrm{P}-6 \mathrm{~K}$ with added micronutrients at a rate of $270 \mathrm{~kg} /$ acre in late March and again in early October.

\section{Description}

'Delicious' has moderate vine vigor and a semirecumbant growth habit with 3- to 6-cm internodes. Leaves average $8 \mathrm{~cm}$ in length and $7 \mathrm{~cm}$ in width, are chordate with dentate margins, and are apubescent. Leaf lower surfaces are light green and glabrous, whereas upper surfaces are darker green, becoming somewhat rugose with aging. Petioles may be shorter or longer than leaf midrib. Tendrils are unbranched, develop opposite of leaves, but are somewhat discontinuous along shoots. New shoots from dormant buds typically produce inflorescences at the third and fourth nodes. Inflorescences are compound panicles composed of eight to 16 flower clusters, each containing three to 15 individual self-fertile (perfect hermaphroditic) flowers. Berries are oval in shape, becoming reddish, then dark purple/black on ripening, and $90 \%$ have a dry stem scar. Fruit ripening date varies seasonally but tends to occur in early August at Apopka, $\approx 2$ to 3 weeks earlier than other muscadine cultivars evaluated in the field trial. Early ripe fruit have a semicrunchy flesh and an edible skin that fragments easily with the flesh. Fruit allowed to ripen further tend to have a softer flesh, become noticeably juicier, but retain an edible skin. Fruit yield is greater, berries are larger with a drier stem scar percentage, and ripen more uniformly than 'Alachua', which also was selected for even ripening (Table 1). Yield and berry size of 'Delicious' are similar to that of 'Nesbitt'; however, the latter ripens unevenly and has poorer stem scar characteristics. 'Southern Home', a Muscadinia $\times$ Euvitis hybrid (Mortensen et al., 1994), has higher soluble solids and ripens evenly, but 'Delicious' exceeds it in all other characteristics. Supreme, a cultivar with remarkably large berries and excellent fruit characteristics, did not produce an acceptable yield in this vineyard. It is noteworthy that similar results were obtained with 'Supreme' during previous testing at the Central Florida Research and Education Center at Leesburg, FL (data not shown). Data for Fry, a bronze-fruited cultivar and an industry standard for fresh fruit production, was statistically identical to 'Delicious' (data not shown).

Symptoms of Pierce's disease have not been observed in 'Delicious'. Fruit are highly resistant to ripe rot, bitter rot, and black rot [Guignardia bidwellii (Ellis) Viala \& Ravaz f. muscadinii] based on comparative evaluations under conditions of low disease control, in which vines received only one application per year of $\mathrm{CuSO}_{4}$ applied after bud burst.

Although 'Delicious' is being released primarily as a fresh eating grape, it has some potential for wine based on preliminary trials. The soluble solids are fairly high for a muscadine grape $(16.9 \%$ in $2007,18.5 \%$ in 2006), whereas the acidity, $\mathrm{pH}$, and press yields are similar to most varieties used for wine. The flavor characteristics of the wine (2006 vintage) were also good and rated equal to those of 'Carlos' (a popular cultivar for wine) by a panel of 30 winemakers. The color is a medium to light red, generally lighter than many red muscadine wines.

In taste, texture, and dry stem scar percentage, 'Delicious' compares favorably with

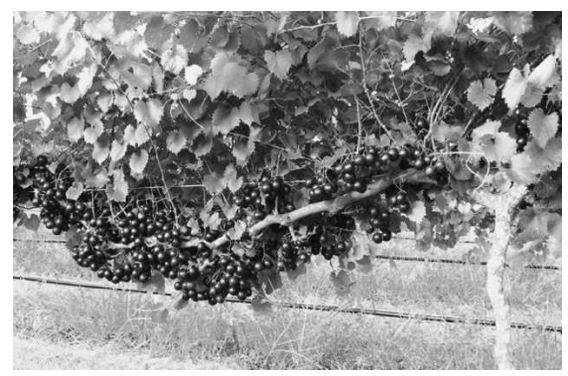

Fig. 1. 'Delicious' muscadine grape.

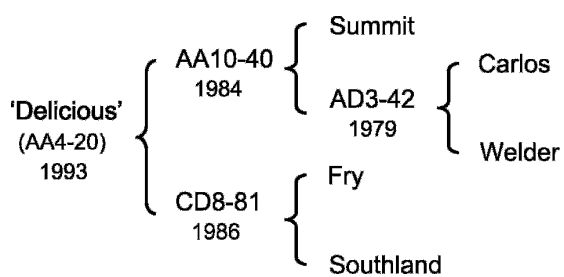

Fig. 2. Pedigree of 'Delicious'. 
Table 1. Flower type, yield, and fruit attributes of 'Delicious' compared with four black-fruited muscadine cultivars grown for fresh fruit consumption. ${ }^{z}$

\begin{tabular}{lcccccc}
\hline Cultivar & $\begin{array}{c}\text { Flower } \\
\text { type }^{\mathrm{y}}\end{array}$ & $\begin{array}{c}\text { Yield/vine } \\
(\mathrm{kg})\end{array}$ & $\begin{array}{c}\text { Fruit with } \\
\text { dry scar }(\%)\end{array}$ & $\begin{array}{c}\text { Berry wt } \\
(\mathrm{g})\end{array}$ & $\begin{array}{c}\text { Soluble solids } \\
\text { concn }(\%)\end{array}$ & $\begin{array}{c}\text { Type of } \\
\text { ripening }\end{array}$ \\
\hline Delicious & $\mathrm{S}$ & $12.86 \mathrm{a}^{\mathrm{x}}$ & $90 \mathrm{a}$ & $10.2 \mathrm{~b}$ & $16.9 \mathrm{~b}$ & Even \\
Alachua & $\mathrm{S}$ & $9.42 \mathrm{~b}$ & $75 \mathrm{~b}$ & $7.0 \mathrm{c}$ & $16.7 \mathrm{~b}$ & Even \\
Nesbitt & $\mathrm{S}$ & $13.07 \mathrm{a}$ & $64 \mathrm{~b}$ & $9.85 \mathrm{~b}$ & $15.8 \mathrm{c}$ & Uneven \\
Southern Home & $\mathrm{S}$ & $9.68 \mathrm{~b}$ & $58 \mathrm{~b}$ & $7.0 \mathrm{c}$ & $18.2 \mathrm{a}$ & Even \\
Supreme & $\mathrm{F}$ & $2.27 \mathrm{c}$ & $96 \mathrm{a}$ & $17.8 \mathrm{a}$ & $17.3 \mathrm{~b}$ & Even \\
\hline
\end{tabular}

${ }^{\mathrm{z}}$ Data are the means from 20 vines of each cultivar from the 2007 harvest with 10 berries per vine evaluated for stem scar, weight, and soluble solids. Data were analyzed by general linear modeling with mean separation within columns by Student-Newman-Keul's test $(P=0.05)$.

${ }^{\mathrm{y}} \mathrm{S}=$ self-fertile (perfect hermaphroditic); $\mathrm{F}=$ female (pistillate hermaphroditic), requiring pollinize.

${ }^{\mathrm{x}}$ Means followed by the same letter were not significantly different.

'Supreme'; however, it is earlier ripening and much more productive at Apopka, albeit smaller in size. It should be useful for both fresh fruit and processing. Although it grows well on deep sandy soils, its adaptation to other regions has not been confirmed.
Florida's Institute of Food and Agricultural Sciences, on 25 Oct. 2007. Inquiries regarding the availability of 'Delicious' should be directed to Florida Foundation Seed Producers, Inc. P.O. Box 110200, Gainesville, FL 32611-0200. A list of nurseries selling Florida-recommended grape varieties may be obtained from most UF/IFAS County Extension Offices.

\section{Literature Cited}

Mortensen, J.A. 2001. Cultivars. p. 91-105. In: Basiouny, F.M. and D.G. Himelrick (eds.). Muscadine grape. ASHS Press, Alexandria, VA.

'Delicious' was publically released by the Cultivar Release Committee of the Florida Agricultural Experiment Station, an agricultural research program of the University of
Mortensen, J.A., J.W. Harris, D.L. Hopkins, and P.C. Andersen. 1994. 'Southern Home': An interspecific hybrid grape with ornamental value. HortScience 92:1371-1372. 